\title{
A comparison between exocytic control mechanisms in adrenal chromaffin cells and a glutamatergic synapse
}

\author{
Erwin Neher
}

Received: 26 May 2006 / Accepted: 24 July 2006 / Published online: 3 October 2006

(C) Springer-Verlag 2006

\begin{abstract}
It has been known since the work of Katz and collaborators in the early 1950 s that an increase in intracellular $\mathrm{Ca}^{++}$concentration $\left(\left[\mathrm{Ca}^{++}\right]\right)$is the immediate trigger for neurotransmitter release [1]. Later work has shown that, next to $\mathrm{Ca}^{++}$, many other signaling pathways, particularly via cyclic AMP, modulate the release of both neurotransmitters and hormones [2-5]. However, regulated secretion is a multistep process and the signaling mechanisms involved act at many stages. Biochemical and traditional electrophysiological techniques very often cannot distinguish whether a change in secretion is caused by regulation of ion channels, vesicle trafficking, or the exocytic process itself. My laboratory has made an effort to dissect the stimulus secretion pathway by developing assays in chromaffin cells (for catecholamine release) and at a glutamatergic central nervous synapse (the calyx of Held, a component of the auditory pathway), which permit the study of secretion in single cells under voltage clamp conditions $[6,7]$. This enables us to clearly distinguish between consequences of changes in electrical signaling, from those regarding the process of vesicle recruitment or the process of exocytosis.
\end{abstract}

Keywords Cyclic AMP $\cdot \mathrm{Ca}^{++}$concentration $\cdot$ Calyx of Held

E. Neher $(\bowtie)$

Max Planck Institute for Biophysical Chemistry,

37077 Goettingen, Germany

e-mail: eneher@gwdg.de

\section{Introduction}

A view into the literature on neurosecretion and its regulation by various second messenger pathways reveals a multitude of potential mechanisms. It is firmly established that the immediate trigger for rapid electrically evoked neurotransmitter release is a localized increase in $\left[\mathrm{Ca}^{++}\right]$ into the range of tens of micromolars [8-10]. However, slow forms of release of neurotransmitters and hormones, which are elicited by modest long-lasting increases of $\left[\mathrm{Ca}^{++}\right]$, can be observed in many cellular systems. Very often, such secretory processes are modulated by other second messengers, such as cyclic AMP (cAMP) and G proteins, and it is often taken for granted that the same mechanisms underlie both the slow and rapid forms of secretion, even more so because rapid, electrically induced secretion is also regulated in many ways by signals other than $\left[\mathrm{Ca}^{++}\right]$. In this short review, an attempt is made to clarify some of the ambiguities resulting from multiple roles of signaling molecules.

In both secretory systems, which we study in our laboratory, we find that not only the final step of triggered exocytosis is dependent on $\left[\mathrm{Ca}^{++}\right]$, but that preceding steps of vesicle recruitment and vesicle priming are also modulated by $\left[\mathrm{Ca}^{++}\right]$and cAMP. Furthermore, it will be pointed out that vesicle-priming steps are highly modulated by second messengers via multiple pathways, whereas the triggering step is relatively robust and hardly affected in its kinetics and $\mathrm{Ca}^{++}$dependence by other influences. The evidence presented here comes from two different secretory systems: nerve terminals and neurosecretory cells. Superficially, secretion control in these systems appears similar in many aspects; however, detailed analysis shows that the 
underlying mechanisms may be quite different. Before addressing these issues, a comparison between methods used to assay secretion in the two preparations is provided.

\section{Methods for studying catecholamine release from adrenal chromaffin cells and glutamate release from the calyx of Held: a comparison}

The method of choice for eliciting exocytosis in my laboratory is to increase $\left[\mathrm{Ca}^{++}\right]$in a step-like fashion by flash photolysis of caged-Ca ${ }^{++}[6,7,11]$. Thereby, $\left[\mathrm{Ca}^{++}\right]$is elevated uniformly in the whole cell or the whole nerve terminal. $\mathrm{A} \mathrm{Ca}^{++}$indicator dye, which is infused into the cell together with the caged compound, provides for the measurement of $\left[\mathrm{Ca}^{++}\right]$in a time-dependent manner. Thus, one can establish a quantitative relationship between the rates of secretion following the UV flash and the $\left[\mathrm{Ca}^{++}\right]$. This approach isolates the $\mathrm{Ca}^{++}$-dependent process and thus reveals possible roles for second messengers in the modulation of this step because it bypasses any modulatory effects that act on electrical excitability and $\mathrm{Ca}^{++}$influx. In addition, we employ voltage clamp depolarization as a stimulus, which is more similar to physiological stimulation. However, the $\mathrm{Ca}^{++}$influx, through discrete channels, produces spatially inhomogeneous $\mathrm{Ca}^{++}$signals in the cytosol, and thus introduces additional complexity. Both types of stimulation are used in both cell types considered here. Most data from chromaffin cells were obtained with flash photolysis, whereas in many Calyx experiments, we use voltage-clamp depolarizations because this allows us to apply multiple stimuli at short intervals.

Secretion is assayed in the two systems in different ways:

1. In adrenal chromaffin cells we use both carbon fiber amperometry, which detects the released catecholamine electrochemically [12], and the electrical membrane capacitance, which is proportional to surface area [13, 14]. Surface area increases when the vesicular membrane becomes part of the plasma membrane during exocytosis. Therefore, as long as exocytosis is fast relative to endocytosis and other forms of membrane retrieval, the capacitance increase is a measure of cumulative exocytosis (see Fig. 1).

2. In the calyx of Held, we measure the excitatory postsynaptic current (EPSC), which is elicited by presynaptically released glutamate. The calyx of Held offers the unique advantage of simultaneous voltage clamp in both the pre- and the postsynaptic compartments. We use the method of deconvolution analysis [15] to calculate release rates (in terms of vesicles released per millisecond) from the measured EPSC.
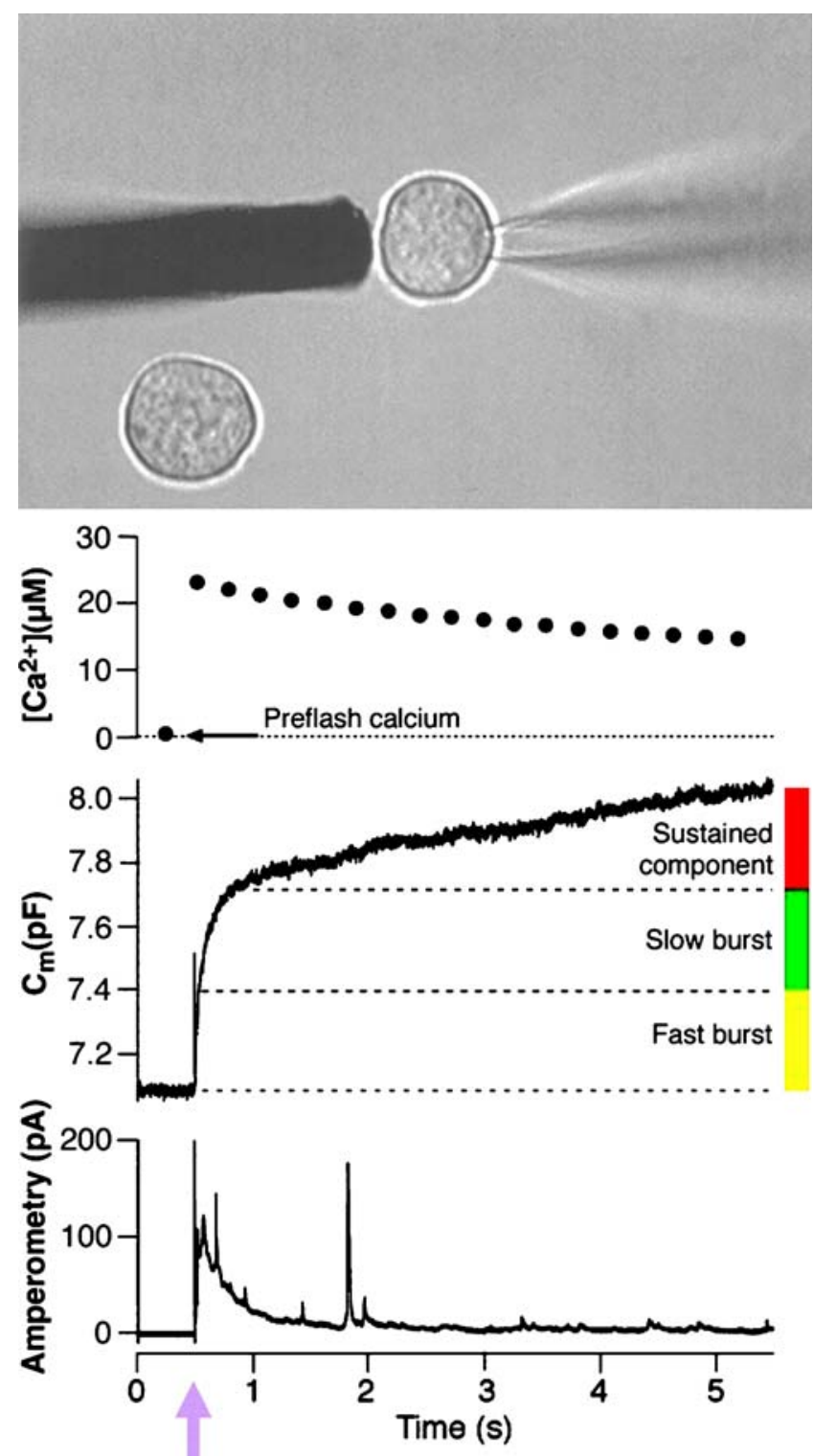

Fig. 1 Techniques to monitor exocytosis in adrenal chromaffin cells. The upper panel shows two chromaffin cells. A micro-carbon fiber is touching one of them, which is also under whole-cell patch clamp. The lower panel shows experimental traces recorded during a caged$\mathrm{Ca}^{++}$flash experiment. The time of the flash is indicated by an arrow (below). The upper-most trace shows $\left[\mathrm{Ca}^{++}\right]$, the middle one the capacitance record, and the lower one the amperometric signal. Note discrete spikes in the latter, which represent exocytosis of single granules near the carbon fiber

In both secretory systems, a so-called "exocytotic burst" can be observed upon sudden elevation of $\left[\mathrm{Ca}^{++}\right]$to a sufficiently high level. The magnitude of this exocytotic burst is proportional to the number of release-competent vesicles. The duration of the burst represents the speed by which these vesicles release at the given $\mathrm{Ca}^{++}$concentration. Once release-competent vesicles have been consumed, exocytosis proceeds at a much slower pace, reflecting "upstream" slower steps of vesicle docking and priming. 
Vesicles, which reach release competence, then undergo exocytosis rapidly as long as $\left[\mathrm{Ca}^{++}\right]$stays elevated following the flash-induced step-like $\left[\mathrm{Ca}^{++}\right]$increase. This delayed response is called the "sustained phase of release". Thus, the observation of an exocytotic burst allows one to discern three mechanistic parameters: first, the amplitude of the burst, which is proportional to the number of releaseready vesicles (or the pool size) immediately before the stimulus; second, the duration of the burst phase, which is an indicator of the rate at which these vesicles are undergoing exocytosis; and third, the release rate during the sustained phase, which reflects vesicle priming.

\section{Robust $\mathrm{Ca}^{++}$-triggering of release-ready vesicles}

Although the details of $\mathrm{Ca}^{++}$-triggering are different between neuroendocrine secretion (in adrenal chromaffin cells) and at nerve terminals, the basic features are quite similar: In both cases, the basic release machinery is made up of similar molecules [16]. The peak rate of release during the exocytotic burst is a steep function of $\left[\mathrm{Ca}^{++}\right]$. In the case of chromaffin cells, the maximum rate of release is best described by a third- to fourth-power function of $\left[\mathrm{Ca}^{++}\right]$with a maximum value of about $10^{3} \mathrm{~s}^{-1}$ at $\left[\mathrm{Ca}^{++}\right]$ $>100 \mu \mathrm{M}$ [6]. This means that it takes, on average, only a few milliseconds of exposure to $50 \mu \mathrm{M}\left[\mathrm{Ca}^{++}\right]$before a release-competent vesicle undergoes exocytosis. For the glutamatergic nerve terminal, the relationship is best fitted by a fourth- to fifth-power dependence, with a maximum rate about tenfold higher [8, 9, 17].

In contrast to this extreme sensitivity towards changes in $\left[\mathrm{Ca}^{++}\right]$, the time course of release during the exocytotic burst is quite robust with respect to influences by other signaling pathways. In neither adrenal chromaffin cells nor nerve terminals is it strongly influenced by manipulations increasing or decreasing cAMP [18] or by manipulating the resting $\left[\mathrm{Ca}^{++}\right]$before the stimulus $[19,20]$. In chromaffin cells, altering the state of SNAP receptor (SNARE) protein phosphorylation or the level of $\mathrm{PIP}_{2}$ does not influence the speed of release, neither do manipulations affecting $G$ proteins (infusion of GTP- $\gamma-S$ or guanosine diphosphate$\beta-S)$ in nerve terminals $[5,21]$. Finally, putting the calyx synapse into a "facilitated" state does not change the $\mathrm{Ca}^{++}$ sensitivity and intrinsic speed of glutamate release at the calyx of Held [20].

Based on the above points, it appears that the $\mathrm{Ca}^{++}$triggering step is relatively robust and not a major target of modulatory pathways, with the one exception of modulation via diacylglycerol [22], (see also recent data on a highly $\mathrm{Ca}^{++}$-sensitive pool [23] and on mutations at "zipper" residues of the SNARE complex [24]). Once the release machinery, consisting of SNARE complexes, calcium sensors (most likely synaptotagmins), and some more accessory proteins (e.g., complexins, Muncs, etc.), is assembled, the calcium concentration seems to be the dominant regulator of release. In contrast, the preceding steps of assembly of the release machinery, as well as the release machinery's localization at the active zone of a synapse, are highly modulated via multiple pathways (see below).

\section{Release-competent vesicles are heterogeneous}

Before switching to the topic of modulation, however, a complication should be addressed: Upon close inspection, the exocytotic burst following a rapid elevation in $\left[\mathrm{Ca}^{++}\right]$ during a caged-Ca ${ }^{++}$experiment in chromaffin cells shows two kinetically distinct components. This indicates that release-competent chromaffin granules can exist in two different states. One population releases about ten times slower than the other one and the slower variety seems to be a precursor of the faster one [25]. Therefore, the two burst components may represent different states of progression of the release machinery. Most of the regulatory steps in vesicle recruitment, to be described below, seem to be "upstream" of this maturation step in the sense that they influence the total amplitude of the exocytotic burst, but not the ratio between its components [6].

When depolarizations are applied to an adrenal chromaffin cell, the ensuing $\mathrm{Ca}^{++}$influx releases a fraction of the vesicles more efficiently then the remainder. This subpool was called the "immediately releasing pool" [25]. It seems to represent those vesicles that both undergo intrinsically fast fusion and are located near $\mathrm{Ca}^{++}$channels. In other words, the intrinsically fast pool is subdivided as a consequence of differential coupling to $\mathrm{Ca}^{++}$influx.

In the calyx of Held, $\mathrm{Ca}^{++}$influx reveals two secretory components of about equal amplitude but of different intrinsic speeds. However, in this preparation, the two components have, so far, mainly been characterized by means of long-duration electrical stimulation and not in caged $\mathrm{Ca}^{++}$experiments. Current investigations (see below) address the question of whether the two components reflect different intrinsic properties of the release apparatus (as is the case for the majority of our chromaffin cell experiments) or different locations of vesicles relative to nearby $\mathrm{Ca}^{++}$channels [26].

\section{Highly modulated vesicle priming in chromaffin cells}

This section on vesicle priming will focus on caged $\mathrm{Ca}^{++}$ experiments on chromaffin cells. Because $\mathrm{Ca}^{++}$is uniformly elevated in these experiments, the localization of 
vesicles at specialized release sites is not of major relevance. Rather, such experiments directly test the intrinsic properties of the release apparatus. Both the amplitude and the time course of the exocytotic burst depend on $\left[\mathrm{Ca}^{++}\right]$. Whereas, the speed of the burst is only a function of the $\left[\mathrm{Ca}^{++}\right]$level reached after the uncaging flash, the amplitude of the burst depends quite strongly on a number of other parameters, above all on the $\left[\mathrm{Ca}^{++}\right]$level before the flash [27]. When changing preflash $\left[\mathrm{Ca}^{++}\right]$from 50 to $300 \mathrm{nM}$, the size of the exocytotic burst changes from about 50 to $300 \mathrm{fF}$, which means that at low $\left[\mathrm{Ca}^{++}\right]$there were about 20 release-competent vesicles present at the time of the flash, and at high $\left[\mathrm{Ca}^{++}\right]$there were about 120 release-competent vesicles. Because this priming step represents the maturation of a subset of morphologically docked vesicles [28], it most likely involves the assembly of the release machinery (the initiation of SNARE complex formation and possibly its interaction with accessory proteins such as complexins and synaptotagmins), which turned out to be $\mathrm{Ca}^{++}$-dependent. Furthermore, the sustained component of release (i.e., the steady rise in capacitance during prolonged elevation of $\left[\mathrm{Ca}^{++}\right]$) indicates a rate of vesicle priming after a flash-induced $\left[\mathrm{Ca}^{++}\right]$ increase, which is an order of magnitude higher than that at resting $\left[\mathrm{Ca}^{++}\right]$. Also, vesicles can be rapidly "deprimed" when basal $\left[\mathrm{Ca}^{++}\right]$is lowered $[29,30]$. Thus, the basal $\left[\mathrm{Ca}^{++}\right]$level is an important dynamic regulator of the number of release-ready vesicles.

Next to the basal $\left[\mathrm{Ca}^{++}\right]$level, the size of the exocytotic burst is regulated by several other signals, such as the $\mathrm{PIP}_{2-}$ level [31], substances influencing protein kinase C-activity [32], the expression level of munc-13 [33], and manipulations influencing cAMP-levels [18]. In addition, we wanted to test whether phosphorylation of SNARE proteins is involved in the regulation of vesicle priming. Because phosphorylation reactions may occur at many proteins involved in the steps leading to secretion (such as vesicle transport, docking, and priming), we chose a method that would allow us to focus on phosphorylation at a specific site in a specific protein. The protein SNAP25 is part of the SNARE complex, which forms the core of the release machinery [34]. It has been shown to be phosphorylated in a cAMP-dependent manner at $\mathrm{Thr}^{138}$ [35]. To test whether this phosphorylation regulates secretion in vivo, a mutant SNAP25, in which $\mathrm{Thr}^{138}$ was either replaced by a phosphomimetic residue (glutamate) or by a nonphosphorylatable alanine, was overexpressed in adrenal chromaffin cells. Experiments in these cells showed that the phosphomimetic isoform left kinetics and amplitude of the secretion process unchanged, while the nonphosphorylatable form supported only a strongly reduced exocytotic burst, without changing the time course of the reduced release [18]. These results mirrored previous pharmacological experiments in the sense that decreased cAMP levels reduced catecholamine release, whereas manipulations, which increased cAMP levels (e.g., applying forskolin or adding cAMP), were without effect. Therefore, it seems that basal cAMP levels are high enough in our experimental conditions to secure the phosphorylated state, while reducing cAMP or cAMP-dependent phosphorylation decreases the number of release-competent vesicles.

Kinetic analysis of the effect indicated that overexpression of the alanine mutant altered only the size of the exocytotic burst but not its time course. These data are best interpreted by assuming that the process of exocytosis is not influenced by the phosphorylation state of SNAP25, but that the phosphorylated form is able to form a more stable release machinery. Thus, the phosphorylated SNAP25 would be able to support a larger pool of release-competent vesicles. This type of regulation of vesicle pool size by cAMP seems to be quite similar in the case of insulinreleasing beta cells of the pancreas [36]. However, in the beta-cell preparation, strong phosphatases shift the equilibrium towards the nonphosphorylated form. Therefore, cAMP has to be elevated to produce a large standing pool.

\section{Two vesicle pools and their modulation at the calyx of Held}

A long-lasting $(50 \mathrm{~ms})$ depolarization to about $-10 \mathrm{mV}$, applied to the calyx of Held, elicits an inward $\mathrm{Ca}^{++}$current of about -1 to $-2 \mathrm{nA}$, exhibiting little or no inactivation during the duration of the stimulus. The exocytotic burst phase, elicited by such a depolarization, has many features in common with flash responses in chromaffin cells, e.g., two distinct kinetic phases. Nevertheless, it turns out that the causes for kinetic heterogeneity among vesicles may not be the same. Likewise, the mechanisms of regulation of vesicle recruitment after a depleting pulse are quite different (see below). In adrenal chromaffin cells, modulators alter the size of the release-ready vesicle pools (i.e., the number of vesicles), while at the calyx of Held the sizes of the two pools are relatively constant for a given terminal. It is, rather, the rate of recovery that was found to be modulated in most of our experiments. A possible reason for this difference may reside in the fact that nerve terminals have very specialized active zones with well-defined binding sites for vesicles [37, 38], whereas adrenaline release from chromaffin cells can occur throughout the cell surface. Active zones may change in shape and number over a long time scale [39], but within the short time span of our experiments the number of specialized docking sites for vesicles are expected to be relatively constant. The existence of specialized active zones with high $\mathrm{Ca}^{++}$ channel density, combined with the morphological finding 
that vesicles also dock at some distance from them, may be a reason for kinetic heterogeneity in the depolarization experiments, which is not relevant in our caged $\mathrm{Ca}^{++}$ experiments on adrenal chromaffin cells. Thus, the finding that both cell types display kinetically distinct vesicle populations may be coincidental.

When the nerve terminal is depolarized to elicit maximal $\left[\mathrm{Ca}^{++}\right]$influx, on average, six vesicles are released per active zone (or 3,000 in total) before the synapse is exhausted (see Fig. 2). Three of these vesicles release rapidly with a time constant of about $3 \mathrm{~ms}$, and the remaining three release reluctantly-about tenfold slower. Following such a strong stimulus, the reluctantly releasing vesicles are regenerated very rapidly, whereas rapidly releasing vesicles become available again only after several seconds [26, 40]. Absolute numbers of such vesicles are quite variable among different cells. However, at a given synapse the two varieties are always roughly equal in number and pool sizes are not modulated in any major way. The only agent so far known to moderately shift the relative proportion in favor of the rapidly releasing component is cAMP [41]. However, this second messenger has another modulatory action that becomes apparent after both pools have been depleted by a strong stimulus: The rate of recruitment of new vesicles to the rapidly releasing pool is enhanced when cAMP is present at a sufficient level [5] and $\left[\mathrm{Ca}^{++}\right]$is elevated at the same time. This enhancement by $\left[\mathrm{Ca}^{++}\right]$has been described before in several types of synapses, including the calyx [40, 42]. Our experiments

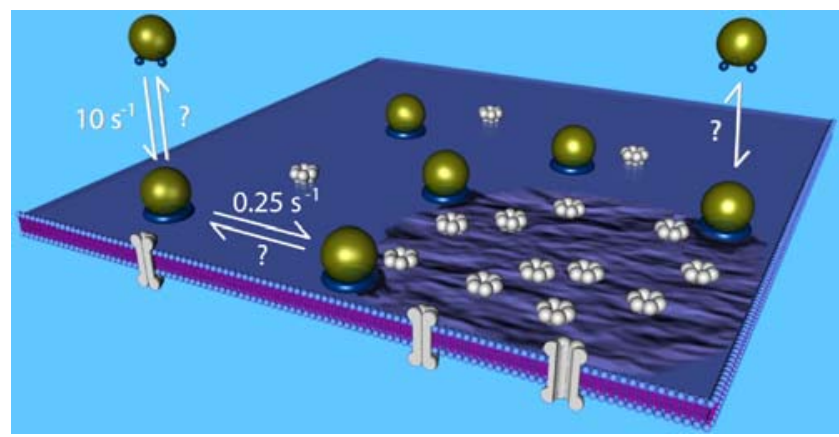

Fig. 2 A hypothesis about positional heterogeneity of vesicles at the Calyx of Held. Three rapidly releasing vesicles docked at the active zone and 3 randomly placed reluctantly releasing vesicles are shown. $\mathrm{Ca}^{++}$-channels are present at high density at the active zone and sparsely in its surrounding, such that the "reluctant" vesicles are less tightly coupled to the $\mathrm{Ca}^{++}$-influx. Reluctant vesicles are recruited very rapidly and may undergo rapid docking-undocking like 'newcomers', observed in total internal reflection microscopy (TIRF, [45]). Rapidly releasing vesicles first dock at the membrane, and then - in a slower process - attach to active zone components, which brings them closer to $\mathrm{Ca}^{++}$channels. This interaction need not be a direct binding of SNARE complexes to $\mathrm{Ca}^{++}$channels, but may be mediated by interactions between components of the release machinery (i.e. SNARES, Munc13) and active zone proteins, such a Rim. After treatment with TeNT the sites of such interactions might be blocked by vesicles with cleaved synaptobrevin showed that it could be prevented when cAMP was lowered by various means. Moreover, this effect was not mediated by A-kinase and phosphorylation, but rather through a cAMP target similar to EPAC (a cAMP-dependent nucleotide exchange factor) [5].

Most of the modulatory actions on the recruitment of vesicles to the rapidly releasing pool described so far alter the speed of vesicle recruitment, not pool sizes. All manipulations regarding basal $\left[\mathrm{Ca}^{++}\right]$and cAMP levels influence the rapidly releasing pool; none act on reluctantly releasing vesicles. Nevertheless, such modulation should be of major importance for the regulation of synaptic strength and short-term depression. It was recently shown that neurotransmitter release evoked by action potentials relies mainly on the rapidly releasing vesicles - those that are subject to modulation [43]. Furthermore, an understanding of why some vesicles are "reluctant" and others not so may be key to a number of other mechanistic issues. In principle, the two types of vesicle may differ in the intrinsic properties of their release apparatus or may occupy different locations relative to nearby $\mathrm{Ca}^{++}$channels, as discussed above. In the latter scenario, vesicles would "see" different $\left[\mathrm{Ca}^{++}\right]$signals when $\mathrm{Ca}^{++}$channels open briefly during electrical stimulation. They would release at different rates, although they might be intrinsically very similar.

Caged $\mathrm{Ca}^{++}$experiments should allow one to distinguish whether the vesicle population is intrinsically heterogeneous or whether differential rates of release are caused by differential coupling to $\mathrm{Ca}^{++}$channels. Such experiments have been performed and, indeed, show intrinsic heterogeneity among vesicles (Woelfel et al. 2003, Neurosc. Abstract). However, recent experiments utilizing neurotoxins to dissect steps in the secretion path provided evidence that differential coupling to channels may play an important physiological role [44]. In this study it was shown that the light chains of tetanus toxin (TeNT) and botulinum neurotoxin type $\mathrm{C} 1$ (BoNT/C1) blocked transmission completely when infused into the presynaptic terminal and when enough time for toxin action was allowed. Also, both toxins acted in an all-or-nothing fashion when release was elicited by photolysis of caged $\mathrm{Ca}^{++}$. More specifically, shortly after exposure, when toxin had affected only a fraction of vesicles, the release kinetics of remaining vesicles were hardly altered. For flashes to relatively high $\left[\mathrm{Ca}^{++}\right]$levels (reflecting levels reached during action potential stimulation), the response could be described by a single exponential in most cases, without any apparent difference between the two toxins. However, when release was tested by depolarization, it was observed that TeNT preferentially blocked the rapidly releasing component, while BoNT/C1 blocked both components alike. Because the caged $\mathrm{Ca}^{++}$experiment excluded intrinsic differences between vesicles as the cause for such 
differential action, an explanation may well be provided by differential coupling between vesicles and $\mathrm{Ca}^{++}$channels. It was suggested [44] that vesicles with toxin-compromised SNARE complexes would occupy specific sites near $\mathrm{Ca}^{++}$ channels at active zones and thereby prevent the docking of intact vesicles at these sites. While intact vesicles docking at alternative sites would still be releasable at full speed by a caged-Ca ${ }^{++}$flash, they would no longer qualify as rapidly releasing ones in the depolarization experiment because their average distances to $\mathrm{Ca}^{++}$channels should be larger (see Fig. 2).

\section{Summary and perspective}

The release of neurotransmitters and hormones is regulated by a variety of intracellular signal pathways. Common to both types of release is a rapid $\mathrm{Ca}^{++}$-dependent triggering mechanism, which is relatively robust towards influences by modulators. Modulation of the release process occurs largely by adjusting the number of release-competent vesicles or the speed by which new vesicles become release-competent. In the case of adrenaline release, the basal $\left[\mathrm{Ca}^{++}\right]$level, $\mathrm{PIP}_{2}$, and the state of phosphorylation of SNAP25 are important modulators of a dynamically regulated pool size. Regulation of glutamate release from nerve terminals shares the same signaling pathways. However, for nerve terminals, the regulation mainly relates to the speed of resupply of releasable vesicles following their depletion by exocytosis, while their steady state numbers seem to be relatively constant and determined by a fixed number of docking sites at the active zone.

How can the two schemes be merged? A solution may be offered by total internal reflection microscopy. Zenisek, Steyer, and Almers [45] used this technique to observe individual fluorescently labeled synaptic vesicles as they approach the membrane and either become docked and fuse or disappear again after a short while. They distinguished between "residents" and "newcomers". The former were vesicles with long residence times, which were only observed at a few specific docking sites. The newcomers also docked at other locations. However, upon stimulation, they fused only after longer delays while residents fused more rapidly. Remarkably, residence times of newcomers were quite short in the absence of stimulation - on the order of a few seconds. The short residence times indicate that the docked, fusion-competent state is readily reversible.

Many of the features observed at the calyx of Held can be well explained assuming that the rapidly releasing vesicles, which mediate most of the evoked release, are "residents" in the sense of Zenisek et al. [45] (see Fig. 2). Their steadystate number at rest is limited by a finite number of docking sites at active zones. The recruitment process to these sites changes in speed, not in extent, upon modulatory actions. The "reluctant" vesicles at the calyx of Held would be "newcomers," docking at less favored sites (at greater distances from active zone components and $\mathrm{Ca}^{++}$channels) much more rapidly and more transiently. Chromaffin granules would all qualify as "newcomers" in this scheme (except for the so-called immediately releasable pool; see above). Because they do not dock at special sites, the number of docked granules is regulated in a dynamic way by the balance of recruitment and detachment. The processes influencing vesicle pool size in chromaffin cells may then be similar to those controlling the pool size of reluctant vesicles, although on a much slower time course. Priming and depriming of chromaffin granules happens on a timescale of $10 \mathrm{~s}$, while the time scale for recovery of the reluctant pool of calyx vesicles is $200 \mathrm{~ms}$.

Two intriguing questions emerge from such a scheme (Fig. 2):

1. Are reluctant vesicles heterogeneous in their intrinsic fusion kinetics, as is the case in chromaffin cells? This is difficult to answer with depolarization experiments because varying distances to the nearest $\mathrm{Ca}^{++}$channels will render them kinetically heterogeneous and compromise the measure of their intrinsic rate of fusion [46]. The rapidly releasing vesicle pool, on the other hand, seems to be more homogeneous, possibly by stabilization through interactions with active zone components.

2. Are reluctant vesicles (newcomers) "precursors" of the rapidly releasing vesicles at the calyx of Held? In other words: do they become residents by laterally moving towards the active zone and docking at special sites (as illustrated in Fig. 2)? To test such a scheme one would have to manipulate the number of available visitors and test for concurrent changes in the recruitment of residents. Such an experiment has been done [47] and, indeed, showed that disruption of the cytoskeleton by latrunculin slows down the recruitment of reluctant vesicles and at the same time delays the recovery of rapidly releasing vesicles.

It is not known at present whether reluctant vesicles are indeed "visitors" and rapidly releasing ones are "residents". Neither can it be excluded that the disruption of the cytoskeleton acts in parallel to influence the recruitment of the two separate populations of vesicles. However, if the mechanisms proposed in Fig. 2 were applicable, the meaning of the terms "recruitment of vesicles" or "recovery from short-term depression" at glutamatergic synapses would have to be reinterpreted. Because the relevant vesicles for evoked release are rapidly releasing [43], the rate-limiting step for their recruitment would not be the docking of vesicles and the accumulation of mature SNARE complexes, but rather a lateral structural rear- 
rangement near the active zone. Modulatory influences by $\left[\mathrm{Ca}^{++}\right]$, cAMP, and/or other signaling pathways on this process might then relate much more to active zone organization than to vesicle priming. In this sense, shortterm modulation at the presynaptic side may be quite similar to that at the postsynapse, where dynamic reorganization of the components of the postsynaptic density has emerged as a dominating theme in the regulation of synaptic plasticity $[48,49]$.

Above all, it should be emphasized that an additional and completely separate complement of regulatory mechanisms influences the ion channels at the synapse, which control the time course of the presynaptic action potentials, as well as the resulting $\mathrm{Ca}^{++}$influx.

\section{References}

1. Katz B (1966) Nerve, muscle and synapse. McGraw-Hill, New York

2. Byrne JH, Kandel ER (1996) Presynaptic facilitation revisited: state and time dependence. J Neurosci 16:425-443

3. Trudeau LE, Emery DG, Haydon PG (1996) Direct modulation of the secretory machinery underlies PKA-dependent synaptic facilitation in hippocampal neurons. Neuron 17:789-797

4. Seino S, Shibasaki T (2005) PKA-dependent and PKA-independent pathways for cAMP-regulated exocytosis. Physiol Rev 85:1303-1342

5. Sakaba T, Neher E (2003) Direct modulation of synaptic vesicle priming by $\mathrm{GABA}_{\mathrm{B}}$ receptor activation at a glutamatergic synapse. Nature 424:775-778

6. Sørensen JB (2004) Formation, stabilisation and fusion of the readily releasable pool of secretory vesicles. Pflugers Arch 448:347-362

7. Rettig J, Neher E (2002) Emerging roles of presynaptic proteins in $\mathrm{Ca}^{++}$-triggered exocytosis. Science 298:781-785

8. Bollmann J, Sakmann B, Borst J (2000) Calcium sensitivity of glutamate release in a calyx-type terminal. Science 289:953-957

9. Schneggenburger R, Neher E (2005) Presynaptic calcium and control of vesicle fusion. Curr Opin Neurobiol 15:266-274

10. Bollmann JH, Sakmann B (2005) Control of synaptic strength and timing by the release-site $\mathrm{Ca}^{2+}$ signal. Nat Neurosci 4:402-404

11. Ellis-Davies GC (2003) Development and application of caged calcium. Methods Enzymol 360:226-238

12. Chow RH, von Rüden L, Neher E (1992) Delay in vesicle fusion revealed by electrochemical monitoring of single secretory events in adrenal chromaffin cells. Nature 356:60-63

13. Neher E, Marty A (1982) Discrete changes of cell membrane capacitance observed under conditions of enhanced secretion in bovine adrenal chromaffin cells. Proc Natl Acad Sci USA 79:6712-6716

14. Gillis KD (2000) Admittance-based measurement of membrane capacitance using the EPC-9 patch-clamp amplifier. Pflugers Arch 439:655-664

15. Sakaba T, Schneggenburger R, Neher E (2002) Estimation of quantal parameters at the calyx of Held synapse. Neurosci Res 44:343-356

16. De Camilli P, Jahn R (1990) Pathways to regulated exocytosis in neurons. Annu Rev Physiol 52:625-645

17. Schneggenburger R, Neher E (2000) Intracellular calcium dependence of transmitter release rates at a fast central synapse. Nature 406:889-893
18. Nagy G, Reim K, Matti U, Brose N, Binz T, Rettig J, Neher E, Sørensen JB (2003) Regulation of releasable vesicle pool sizes by protein kinase A-dependent phosphorylation of SNAP-25. Neuron 41:417-429

19. Voets $\mathrm{T}(2000)$ Dissection of three $\mathrm{Ca}^{2+}$-dependent steps leading to secretion in chromaffin cells from mouse adrenal slices. Neuron 28:537-545

20. Felmy F, Neher E, Schneggenburger R (2003) Probing the intracellular calcium sensitivity of transmitter release during synaptic facilitation. Neuron 37:801-811

21. Takahashi T, Hori T, Kajikawa Y, Tsujimoto (2000) The role of GTP-binding protein activity in fast central synaptic transmission. Science 289:460-463

22. Lou X, Scheuss V, Schneggenburger R (2005) Allosteric modulation of the presynaptic $\mathrm{Ca}^{2+}$ sensor for vesicle fusion. Nature 435:497-501

23. Yang Y, Gillis KD (2004) A highly $\mathrm{Ca}^{2+}$-sensitive pool of granules is regulated by glucose and protein kinases in insulinsecreting INS-1 cells. J Gen Physiol 124:641-651

24. Sørensen JB, Wiederhold K, Muller EM, Milosevic I, de Groot BL, Grubmüller H, Fasshauer D (2006) Sequential N- to Cterminal SNARE complex assembly drives priming and fusion of secretory vesicles. EMBO J 25:955-966

25. Voets T, Neher E, Moser T (1999) Mechanisms underlying phasic and sustained secretion in chromaffin cells from mouse adrenal slices. Neuron 23:607-615

26. Sakaba T, Neher E (2001) Quantitative relationship between transmitter release and calcium current at the calyx of Held synapse. J Neurosci 21:462-476

27. von Rüden L, Neher E (1993) A Ca-dependent early step in the release of catecholamines from adrenal chromaffin cells. Science 262:1061-1065

28. Parsons TD, Coorssen JR, Horstmann H, Almers W (1995) Docked granules, the exocytic burst, and the need for ATP hydrolysis in endocrine cells. Neuron 15:1085-1096

29. Smith C, Moser T, Xu T, Neher E (1998) Cytosolic Ca++ acts by two separate pathways to modulate the supply of releasecompetent vesicles in chromaffin cells. Neuron 20:1243-1253

30. Dinkelacker V, Voets T, Neher E, Moser T (2000) The readily releasable pool of vesicles in chromaffin cells is replenished in a temperature-dependent manner and transiently overfills at $37^{\circ} \mathrm{C}$. J Neurosci 20:8377-8383

31. Milosevic I, Sørensen JB, Lang T, Krauss M, Nagy G, Haucke V, Jahn R, Neher E (2005) Plasmalemmal phosphatidylinositol-4,5biphosphate level regulates the releasable vesicle pool size in chromaffin cells. J Neurosci 25:2557-2565

32. Gillis KD, Mössner R, Neher E (1996) Protein kinase C enhances exocytosis from chromaffin cells by increasing the size of the readily releasable pool of secretory granules. Neuron 16:1209-1220

33. Ashery U, Varoqueaux F, Voets T, Betz A, Thakur P, Koch H, Neher E Brose N, Rettig J (2000) Munc13-1 acts as a priming factor for large dense-core vesicles in bovine chromaffin cells. EMBO J 19:3586-3596

34. Jahn R, Lang T, Südhof TC (2003) Membrane fusion. Cell 112:519-533

35. Risinger C, Bennett MK (1999) Differential phosphorylation of syntaxin and synaptosome-associated protein of $\mathrm{kDa}$ (SNAP-25) isoforms. J Neurochem 72:614-624

36. Renstrom E, Eliasson L, Rorsman P (1997) Protein kinase Adependent and -independent stimulation of exocytosis by cAMP mouse pancreatic B-cells. J Physiol 502:105-118

37. Zucker RS (1973) Changes in the statistics of transmitter release during facilitation. J Physiol 229:787-810

38. Harlow ML, Ress D, Stoschek A, Marshall RM, McMahon UJ (2001) The architecture of active zone material at the frog's neuromuscular junction. Nature 409:479-484 
39. Wimmer VC, Horstmann H, Groh A, Kuner T (2006) Donut-like topology of synaptic vesicles with a central cluster of mitochondria wrapped into membrane protrusions: a novel structure-function module of the adult calyx of Held. J Neurosci 26:109-116

40. Sakaba T, Neher E (2001) Calmodulin mediates rapid recruitment of fast-releasing synaptic vesicles at a calyx-type synapse. Neuron 32:119-1131

41. Sakaba T, Neher E (2001) Preferential potentiation of fastreleasing synaptic vesicles by cAMP at the calyx of Held. Proc Natl Acad Sci USA 98:331-336

42. Wang LY, Kaczmarek LK (1998) High-frequency firing helps replenish the readily releasable pool of synaptic vesicles. Nature 394:384-388

43. Sakaba T (2006) Roles of the fast-releasing and slowly releasing vesicles in synaptic transmission at the calyx of Held. J Neurosci 26:5863-5871
44. Sakaba T, Stein A, Jahn R, Neher E (2005) Distinct kinetic changes in neurotransmitter release after SNARE-protein cleavage. Science 309:491-494

45. Zenisek D, Steyer JA, Almers W (2000) Transport, capture and exocytosis of single synaptic vesicles at active zones. Nature 406:849-854

46. Meinrenken CJ, Borst JG, Sakmann B (2002) Calcium secretion coupling at calyx of Held governed by nonuniform channelvesicle topography. J Neurosci 22:1648-1667

47. Sakaba T, Neher E (2003) Involvement of actin polymerization in vesicle recruitment at the calyx of Held. J Neurosci 23:837846

48. Kennedy MB (2000) Signal processing machines at the postsynaptic density. Science 290:750-754

49. Kim E, Sheng M (2004) PDZ domain proteins of synapses. Nat Rev Neurosci 5:771-781 